\title{
Additive value of dobutamine stress echocardiography in patients with an anomalous origin of a coronary artery
}

\author{
Heleen Lameijer $\cdot$ Jozine M. ter Maaten $\cdot$ Robbert C. Steggerda
}

Published online: 27 January 2015

(C) The Author(s) 2014. This article is published with open access at Springerlink.com

\begin{abstract}
An anomalous origin of a coronary artery (AOCA) is the second most common cause of non-traumatic sudden cardiac death in young athletes. Patients with a malignant course of an AOCA of the right coronary artery only need surgical correction when myocardial ischaemia is detected. An AOCA and its malignant or benign course can be detected by coronary angiography, coronary computed tomography or cardiac magnetic resonance imaging. Detection of ischaemia can be more difficult since even a negative maximal-effort stress ECG does not exclude a potential lethal coronary anomaly. Also, there are no case series or trials showing sensitivity or specificity for any form of ischaemia detection for AOCA in the literature. Although not described previously in adults, dobutamine stress echocardiography was previously described in a paediatric population with AOCA. We are the first to describe ischaemia detection by dobutamine stress echocardiogra-
\end{abstract}

Electronic supplementary material The online version of this article (doi: 10.1007/s12471-014-0648-3) contains supplementary material, which is available to authorized users.

H. Lameijer, MD $(\bowtie) \cdot$ R. C. Steggerda, MD $(\bowtie) \cdot$

J. M. ter Maaten, MD

Department of Cardiology, Martini Hospital,

van Swietenplein 1,

9728 NT Groningen, the Netherlands

e-mail: h.lameijer@umcg.nl

R. C. Steggerda, MD

e-mail: r.c.steggerda@mzh.nl

\section{J. M. ter Maaten, MD}

e-mail: j.m.ter.maaten@umcg.nl

H. Lameijer, MD

Department of Emergency Medicine, University Medical Centre Groningen,

Groningen, the Netherlands phy in three adult patients with an AOCA of the right coronary artery who were subsequently referred for surgery.

\section{Introduction}

An anomalous origin of a coronary artery (AOCA) is the second most common cause of non-traumatic sudden cardiac death in young athletes [1]. Patients diagnosed with a malignant, inter-arterial course of an AOCA of the left coronary artery (Fig. 1) are usually referred for cardiac surgery according to the guidelines. Patients with a malignant course of an AOCA of the right coronary artery (Fig. 2) only need surgical correction when myocardial ischaemia is detected. In three patients with an AOCA of the right coronary artery we detected ischaemia using dobutamine stress echocardiography. For more detailed case descriptions and discussion, see our online supplementary material.

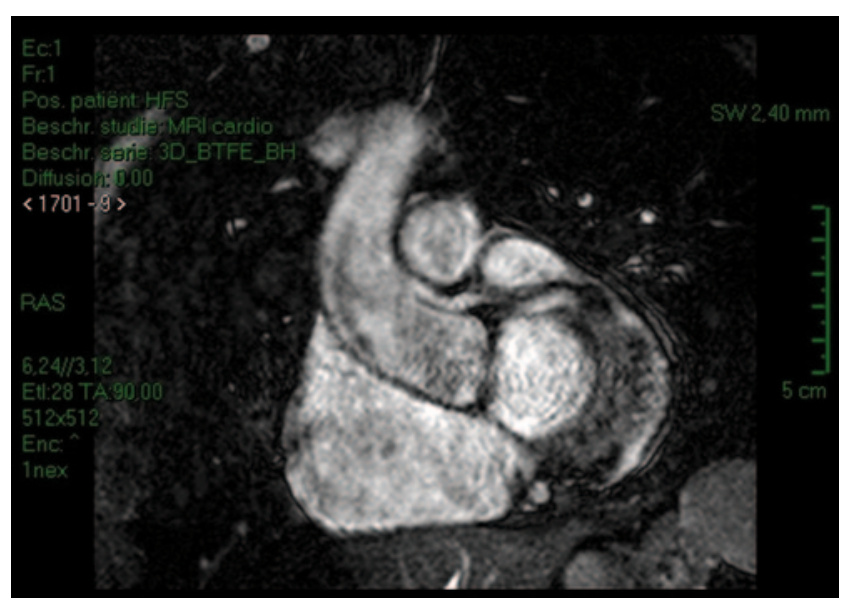

Fig. 1 Coronary angiography of a patient showing an aberrant left coronary artery originating from the right coronary ostium 
Fig. 2 Coronary computed tomography scan of a patient showing an aberrant origin of the right coronary artery with a malignant inter-arterial course

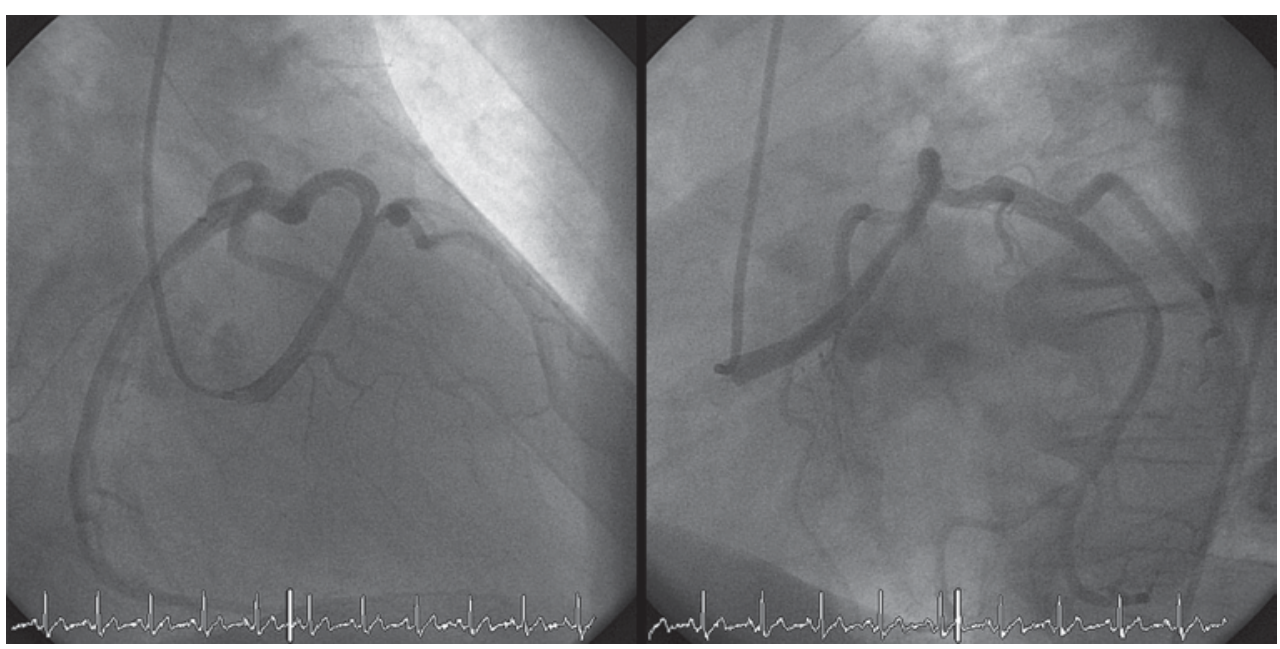

\section{Discussion}

An AOCA and its malignant or benign course can be detected by coronary angiography (best including a right oblique view), coronary computed tomography or cardiac magnetic resonance imaging [2]. Detection of ischaemia can be more difficult since even a negative maximal-effort stress ECG does not exclude a potential lethal coronary anomaly $[1,3$, 4]. Also there are no case series or trials showing sensitivity or specificity for any form of ischaemia detection for AOCA in the literature. Though not described previously in adults, dobutamine stress echocardiography was previously described in a paediatric population with AOCA [5]. We are the first to describe ischaemia detection by dobutamine stress echocardiography in three adult patients with an AOCA of the right coronary artery who were referred subsequently for surgery.

\section{Conclusion}

Since normal routine exercise electrocardiography test does not exclude ischaemia in patients with AOCA, we suggest the use of dobutamine stress echocardiography in patients with AOCA.
Funding resources No funding resources.

Conflict of interest No conflict of interest.

Open Access This article is distributed under the terms of the Creative Commons Attribution License which permits any use, distribution, and reproduction in any medium, provided the original author(s) and the source are credited.

\section{References}

1. Maron BJ, Doerer JJ, Haas TS, Tierney DM, Mueller FO. Sudden deaths in young competitive athletes: analysis of 1866 deaths in the United States, 1980-2006. Circulation. 2009;119:1085-92.

2. Taylor AM, Thorne SA, Rubens MB, et al. Coronary artery imaging in grown up congenital heart disease: complementary role of magnetic resonance and $\mathrm{x}$-ray coronary angiography. Circulation. 2000;101:1670-78.

3. Chu E, Cheitlin MD. Diagnostic considerations in patients with suspected coronary artery anomalies. Am Heart J. 1993;126:1427-38.

4. Basso C, Maron BJ, Corrado D, Thiene G. Clinical profile of congenital coronary artery anomalies with origin from the wrong aortic sinus leading to sudden death in young competitive athletes. J Am Coll Cardiol. 2000;35:1493-501.

5. Kimball TR. Pediatric stress echocardiography. Pediatr Cardiol. 2002;23:347-57. 